\title{
Cine e Historia. Reflexiones sobre la imagen política en el Cine Contemporáneo Proyecto de Investigación 14.1 Equipo de Investigación
}

Zulema Marzorati y Mercedes Pombo por Facultad de Diseño y Comunicación, Universidad de Palermo (ARG) y Fernando Mazás por Universidad del Cine (ARG)

Línea de Investigación 14.

Cine y Sociedad. Reflexiones sobre el cine contemporáneo

\begin{abstract}
Resultados publicados en el [Cuaderno 62]
Cuaderno del Centro de Estudios de Diseño y Comunicación No62. (2017) Cine documental. Coordinación Fernando Mazás. Programa de Investigación de la Facultad de Diseño y Comunicación. Centro de Estudios en Diseño y Comunicación. Facultad de Diseño y Comunicación. Universidad de Palermo Año XVII, Julio 2017, Buenos Aires, Argentina. ISSN: 1668-0227.
\end{abstract}

Los resultados de este Proyecto de Investigación fueron evaluados por Ana María Torres y su Dictamen se transcribe a continuación:

\section{Síntesis de la Evaluación}

Actualidad de la temática (Vigencia, Aplicación) / Notable Nivel Alcanzado (Profundidad, Consistencia, Jerarquía) / Notable Diversidad del enfoques (Pluralidad, Participación) / Notable Calidad (Problemática, Análisis, Tratamiento) / Notable Contribución al avance del Diseño (Fortaleza) / Notable

\section{Fundamentos y Comentarios}

Esta investigación aporta cuidadosamente al tema de la producción cinematográfica desde diferentes perspectivas, a través de una gran variedad de escritos que dejan ver la gran oportunidad que tiene la producción audiovisual para el conocimiento de sucesos o hechos históricos relevantes.

Desde el inicio de la investigación se pretende mostrar a partir del prólogo, una introducción que nos lleve a la mejor comprensión de lo que muestran los escritos, a través del punto de vista de un experto, que nos invita a pensar en el documental como un ámbito de pensamiento productivo, esto es muy acertado. 
Se reflexiona sobre la dificultad en establecer modalidades parta el uso de diversos materiales, en las películas que van desde la realidad del hombre hasta lo poético. Esto nos lleva como academia, hacer un análisis sobre los beneficios que traería utilizar en los procesos de enseñanza aprendizaje las películas, los audiovisuales y otros materiales de este tipo, como un recurso atractivo, dentro y fuera del aula cotidianamente.

En este documento se busca aportar nuevas consideraciones, por medio del discurso reflexivo, esta es un trabajo muy interesante, el ver como los autores tratan de explicar con palabras la trama en imágenes de un documental y el cómo hacen su análisis para que puede identificarse la relación entre la realidad y la ficción.

Merece un reconocimiento el trabajo que realiza un análisis desde la parte teórica del campo de la producción, de una obra llevada a través de la producción artística simbólica. No es nada sencilla la selección de una imagen que debe transmitir la realidad y llegar a los espectadores de igual forma y mucho menos tratar de explicar cómo es que se seleccionó para un determinado fin.

Es muy atrayente el buscar que por medio de imágenes del pasado unidas y puestas en movimiento, se pueda generar una nueva manera de ver hacia la historia.

La forma creativa en que los autores de los documentos de esta investigación utilizan un recurso tan sencillo como es la entrevista y hace reflexionar al lector sobre el uso de este recurso como una modalidad particular que impacta tanto de forma individual y colectiva a través de las técnicas audiovisuales.

El pensar cómo desde la psicología y la ideología se pueden persuadir a los individuos, a sentir la necesidad de ver una película. Esto nos hace pensar cómo puedo utilizar estos recursos para persuadir a alguien a ser atraído por los temas que ilustran y amplían el conocimiento.

Es muy interesante la forma en la que nos llevan los autores por diferentes momentos para comprender el porqué del largo metraje a través de la historia. Grabar acontecimientos reales para que queden en la historia como documento fiel, es muy educativo, una imagen dice más que mil palabras.

Los cortos y largo metrajes nos hacen reflexionar sobre acontecimientos significativos, y nos ayudan a que queden en nuestra memoria. Pero el tratar de analizarlos mediante el punto de vista de un autor, nos muestra una perspectiva distinta de acontecimientos que tal vez antes no habíamos identificado, o tal vez antes no habían llamado nuestra atención, esta serie de escritos son un excelente ejemplo que mueve nuestra curiosidad para interesarnos en las películas que se mencionan y la forma en la que las narraciones muestran su análisis, esto es muy bueno, ya que nos lleva a buscar verlas y tratar de ser críticos tal como los autores que los presentan. Esto ayuda a entender la importancia de este significativo material, que ayuda a que la historia no se pierda y quede en nuestra memoria por generaciones, gracias a la utilización del medio audiovisual y de aquellos autores que nos hacen reflexionar sobre los diversos temas que en esta investigación se muestran, muchas gracias. 